CASE STUDY

\title{
Collaborating for Student Success at Valencia College
}

October 29, 2015

Jessie Brown

Martin Kurzweil

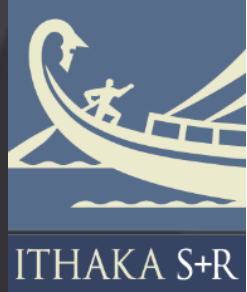




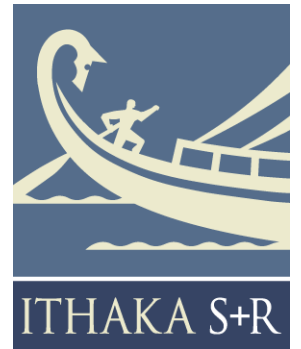

Ithaka $\mathrm{S}+\mathrm{R}$ is a strategic consulting and research service provided by ITHAKA, a not-for-profit organization dedicated to helping the academic community use digital technologies to preserve the scholarly record and to advance research and teaching in sustainable ways. Ithaka $\mathrm{S}+\mathrm{R}$ focuses on the transformation of scholarship and teaching in an online environment, with the goal of identifying the critical issues facing our community and acting as a catalyst for change. JSTOR, a research and learning platform, and Portico, a digital preservation service, are also part of ITHAKA.
Copyright 2015 ITHAKA. This work is licensed under a Creative Commons Attribution-NonCommercial 4.0 International License. To view a copy of the license, please see http://creativecommons.org/licenses/by-nc/4.0/.

ITHAKA is interested in disseminating this case study as widely as possible. Please contact us with any questions about using the case study: research@ithaka.org. 


\section{Introduction}

In recent years, a promising conversation about change at community colleges has emerged. Employing the language of redesign and reinvention, this conversation emphasizes comprehensive, broad-sweeping reform, and calls for a reorientation of community college missions around student learning and student success. Though it is hard to disagree that improving student outcomes is desirable, the traditional enrollment and funding models for community colleges make a true institutional "reset" difficult. Understanding how institutions have successfully gone about redesigning their operations and culture to promote student success, then, is just as important as advocating that they do so. ${ }^{1}$

Valencia College, a five-campus community college that in 2014-15 served more than 60,000 students in and around Orlando, Florida, provides a particularly illuminating example of large-scale change to institutional culture, with dramatic effects on student success. Between 2005 and 2014, Valencia more than doubled the number of associate's degrees it awarded, through a combination of a large increase in degree-seeking students and a ten-point increase in its five-year completion rate. Improvements in fall-to-spring persistence rates, developmental education pass rates, credit-attainment, and transfer rates are equally impressive. Notably, Valencia has achieved these improvements in outcomes while keeping student costs exceptionally low: over the past five years, Valencia's tuition has increased once, by a mere four dollars per credit hour.

\section{Valencia has achieved these improvements in outcomes while keeping student costs exceptionally low: over the past five years, Valencia's tuition has increased once, by a mere four dollars per credit hour.}

What makes a study of Valencia's transformation so fruitful is the deliberate and selfconscious way in which its leaders have endeavored to shift the culture. Valencia has embraced an approach that president Sandy Shugart calls "collaborative design."

\footnotetext{
${ }^{1}$ See, for example, Thomas Bailey, Shanna Jaggers and Davis Jenkins, Redesigning America's Community Colleges: $A$ Clearer Path to Student Success (Cambridge: Harvard University Press, 2015) and "Reclaiming the American Dream: Community Colleges and the Nation's Future," American Association of Community Colleges, Washington D.C. (2012), https://www.insidehighered.com/sites/default/server files/files/21stCentReport.pdf, which advocates that community colleges "redesign students' educational experiences, reinvent institutional roles, and reset the system."
} 
Distinct from garnering buy-in, collaborative design incorporates insights from stakeholders from various departments and levels into program design and implementation, and is grounded in a process of inquiry rather than advocacy for predetermined outcomes. It is guided by the notion that the most effective ideas for promoting student success come from those stakeholders who work on the "front-lines" with students (such as faculty and support staff), and propelled by the belief that the best way to develop these ideas into broadly adopted practices is through collaborative analysis and decision-making. ${ }^{2}$

To learn more about Valencia's approach to collaborative design, we visited Valencia's West Campus for two days in June of 2015. During our visits, we met with a dozen students, administrators, and advisors. We also attended the final day of Destination, Valencia's annual faculty development program, where we engaged with faculty members who were presenting their plans to improve and measure student learning in their courses.

The distinct processes and structures that Valencia has developed to facilitate collaborative design include a flexible shared governance model, annual Big Meetings in which hundreds of faculty and staff reflect on institutional data and develop institutional priorities, and Valencia's Big Ideas, a set of shared principles that guide decisionmaking. One noteworthy set of processes is Valencia's uniquely robust faculty development programs. It is through these programs that Valencia faculty members learn about, elaborate, and integrate organization-wide initiatives. In addition, these programs provide a forum for surfacing and incubating faculty innovations.

To illustrate the collaborative design and faculty development processes at Valencia, we discuss several of Valencia's student success initiatives, and focus more extensively on two. First, we examine the collaborative process through which Valencia works with the University of Central Florida and other state college partners to continuously refine DirectConnect to UCF, a transfer coordination program. Then, we document the initial design of the New Student Experience, Valencia's latest portfolio of learning-centered interventions focused on providing support to students as they earn their first fifteen credits at Valencia. Each of these initiatives demonstrates Valencia's reliance on datadriven inquiry as a starting point for design; the mutual trust amongst faculty, staff, and administrators; and the structures through which faculty and staff experiences are surfaced, articulated, and incorporated into full-scale reforms.

\footnotetext{
${ }^{2}$ For a video in which President Shugart articulates this principle, see "Collaboration and Engagement" at http://valenciacollege.edu/trustee-education/valenciasbigideas.cfm.
} 


\section{Origins and Operations}

\section{Collaborative Design}

Valencia's collaborative design process, which was first articulated in the early 200os, has roots in an earlier shift toward a learning-centered model of advising and teaching. In 1994, Valencia began to develop a developmental advising model that encourages students to create educational and career paths early on in their college experiences. ${ }^{3}$ This approach to advising, which came to be called LifeMap, links all of the components of Valencia (faculty, staff, courses, technology, programs, and services) into an integrated and personal itinerary to help students progress from their transition into college to graduation and onto transfer or employment. Grounded in developmental theories of education, LifeMap emphasizes student progress from reliance on the "Big A," the advisor, to navigate her academic and career pathway, to self-reliance on the "Big S," the student, with shared responsibility along the way. In planning and implementation of LifeMap, administrators, faculty, and students began to conceptualize Valencia as a pathway to learning, graduation, and opportunity for enrolled students. This mindset has defined Valencia's mission and strategic initiatives ever since.

\section{Valencia's collaborative design process, which was first articulated in the early 2000s, has roots in an earlier shift toward a learning-centered model of advising and teaching.}

In 1995, shortly after Valencia began to design LifeMap, the college launched the "Learning Centered Initiative."4 Initially funded by Title III and Title V grants and by the Kellogg Foundation, the Learning Centered Initiative was designed to "institutionalize effective innovations and to focus on improving measureable outcomes" for students. Though the initiative remained, in its early years, a "fringe" movement within the institution, it became a focus for a number of senior faculty and administrators, laid the

\footnotetext{
3 "LifeMap," Valencia College, http://valenciacollege.edu/lifemap/. See also, Joyce Romano, "Valencia College: A learning centered student advising system," in Terry O'Banion (ed.), Academic Advising: The Key to Student Success (Washington D.C.: Community College Press AACC, 2013), p. 33-56.

${ }^{4}$ For an overview of the Learning Centered Initiative and its design process, see Valencia's first Strategic Learning Plan (2001-2004), available at http://valenciacollege.edu/lci/essays/plan.pdf. See also "The Learning Centered Initiative," Valencia College, http://valenciacollege.edu/lci/. Because of its early learning-centered work, Valencia was recognized in 2000 by the League for Innovation in the Community College as one of 12 international Vanguard Learning Colleges.
} 
groundwork for future student success initiatives, and served as a testing ground for many of the participatory processes that would drive those later initiatives' development.

In 2000, Valencia's Board of Trustees hired Sandy Shugart as president. The early successes of LifeMap and the Learning Centered Initiative contributed to Valencia's appeal to Shugart; for its part, the Board viewed Shugart as a leader who could bring student success from the fringes to the center of Valencia's culture. In his 15 years as president, Shugart's approach to leadership has solidified a data-driven, inquisitive, broad-based approach to planning as the primary vehicle for bringing about institutional change.

Notwithstanding the Learning Centered Initiative, when Shugart arrived at Valencia, the dominant culture within the institution was still what he calls a "culture of stewardship," which valued increases in enrollment and reproved increases in spending. To shift the focus to student learning, Shugart made three early changes to undermine the culture of stewardship. First, he addressed resource allocation. Shugart directed Valencia's CFO to produce a complete, transparent budget and shared it with the board, administrators, and the faculty. He then introduced a new process for budgeting that was based on furthering the learning goals established through the Learning Centered Initiative. No funds were protected; every dollar could be reallocated to better serve those learning goals. Second, he sought to disrupt the enrollment focus. His primary strategy was to forbid the institutional research office to distribute the frequently updated course enrollment reports on which many administrators and faculty leaders had previously fixated.

Then, with the culture of stewardship muted, Shugart shifted attention to an organization-wide conversation about student success. He began this process in 2001 with a "Big Meeting," a data-focused convening of hundreds of faculty, staff, and administrators that has since become a hallmark of Valencia's planning process. The topic of the first Big Meeting was "what are 10 things we do that are bad for student learning but we think we have to do for other reasons?" In this Big Meeting and in follow-up meetings throughout the college, dozens of illustrations were offered. Some examples included: late registration, drop-add, poor enforcement of pre-requisites, poorly supported adjunct instructors, privacy of student feedback on instruction, secretiveness of grade distributions, rooms that do not get used, scheduling classes that are sequential during the same semester, and setting the schedule around faculty convenience. 


\section{Valencia's Big Ideas have been foundational in establishing a shared culture, language, and set of principles that can be engaged as stakeholders from across campuses and departments set goals and plan initiatives.}

Rather than point fingers, the purpose of these conversations was to invite faculty, staff, and administrators to engage in a process of self-reflection. In the process of examining the ways in which aspects of the status quo were at odds with beliefs and research about student success, participants also identified concepts and practices that would improve outcomes. Shugart and his leadership team distilled from these conversations a set of "working theories" about how students succeed, how the institution can best help students succeed, and how to effect institution-wide change. Over time, these working theories have crystalized into a growing list of "Big Ideas," described in Table 1.5 Valencia's Big Ideas have been foundational in establishing a shared culture, language, and set of principles that can be engaged as stakeholders from across campuses and departments set goals and plan initiatives.

\footnotetext{
${ }^{5}$ Valencia defines its Big Ideas as "fulcrums for change, signifiers for emerging organizational culture, and rallying points for action." For a conceptual overview, see Sandy Shugart, Joyce Romano, Julie Phelps, Ann Puyana, and Kaye Walter "Valencia's Big Ideas: Sustaining Authentic Organizational Change through Shared Purpose and Culture," http://valenciacollege.edu/academic-affairs/institutional-effectiveness-planning/institutionalassessment/documents/Bigldeaspdfversion.pdf. For a collection of resources, see "Valencia's Big Ideas," Trustee Education and Preparation, http://valenciacollege.edu/trustee-education/valenciasbigideas.cfm.
} 
Table 1. Valencia's Big Ideas

Big Idea Description Implications

\begin{tabular}{|c|c|c|}
\hline $\begin{array}{l}\text { Anyone can learn } \\
\text { anything under the } \\
\text { right conditions }\end{array}$ & $\begin{array}{l}\text { Students have all the } \\
\text { biological gifts, the inherent } \\
\text { capabilities to learn anything } \\
\text { they are taught. }{ }^{6}\end{array}$ & $\begin{array}{l}\text { - Encourages leaders and educators to move } \\
\text { beyond the myth that some students aren't "college } \\
\text { material" } \\
\text { - Shifts focus from the deficiencies of the learners to } \\
\text { the conditions of learning } \\
\text { - Underlies initiatives that aim to create supportive } \\
\text { learning spaces, diverse instructional approaches, } \\
\text { academic support systems, and a welcoming } \\
\text { campus climate }\end{array}$ \\
\hline Start Right & $\begin{array}{l}\text { The greatest challenge and } \\
\text { opportunity for improvement } \\
\text { in student success and } \\
\text { graduation at Valencia is at } \\
\text { the beginning of every new } \\
\text { experience a student has at } \\
\text { the institution. Valencia's } \\
\text { rallying cry is "make the first } \\
\text { minute of the first meeting, in } \\
\text { every course a learning } \\
\text { minute." }\end{array}$ & $\begin{array}{l}\text { Encourages a detailed understanding of students' } \\
\text { - Early college experiences } \\
\text { the front door } \\
\text { - Underlies initiatives that enforce early application } \\
\text { deadlines, required orientations, required entry } \\
\text { testing and prerequisites, success courses for } \\
\text { developmental students, and restricted late adds }\end{array}$ \\
\hline $\begin{array}{l}\text { Connection and } \\
\text { Direction }\end{array}$ & $\begin{array}{l}\text { A student must make a } \\
\text { personal connection very } \\
\text { early in her experience at the } \\
\text { college with staff, with faculty } \\
\text { and with other students. A } \\
\text { student needs clear direction } \\
\text { and a plan to graduate as } \\
\text { soon as possible in her } \\
\text { college career. }\end{array}$ & $\begin{array}{l}\text { - Encourages a focus on helping students make real } \\
\text { connections with college faculty/staff and other } \\
\text { students as early as possible } \\
\text { - Underlies initiatives and LifeMap, Career Program } \\
\text { Advisors and LinC }\end{array}$ \\
\hline $\begin{array}{l}\text { The college is how } \\
\text { the students } \\
\text { experience us, not } \\
\text { how we experience } \\
\text { them }\end{array}$ & $\begin{array}{l}\text { Students are unique } \\
\text { individuals and they } \\
\text { experience college in } \\
\text { powerfully personal ways. } \\
\text { Measures of success should } \\
\text { be found in what students' } \\
\text { experience. }\end{array}$ & $\begin{array}{l}\text { - Encourages a focus on individual student, rather } \\
\text { than aggregate student (e.g. section, cohort, } \\
\text { demographic) as the basic unit of analysis } \\
\text { - When paired with other Big Ideas, supports a model } \\
\text { in which each student experience consists of a } \\
\text { career goal, relationships with others on campus, } \\
\text { high engagement, and increasing self-sufficiency as } \\
\text { they progress to graduation }\end{array}$ \\
\hline
\end{tabular}

\footnotetext{
${ }^{6}$ All descriptions are adapted from Valencia's "We believe" statements, which were drafted to flesh out the implications of each Big Idea. These statements are included in a Power Point presentation entitled "Valencia's Big Ideas: Sustaining Authentic Organizational Change through Shared Purpose and Culture," originally presented at the Achieving the Dream pre-conference meeting, February 2014, provided to us by Kurt Ewen.
} 


\begin{tabular}{|c|c|c|}
\hline $\begin{array}{l}\text { The purpose of } \\
\text { assessment is to } \\
\text { improve learning }\end{array}$ & $\begin{array}{l}\text { The most important } \\
\text { beneficiaries of authentic } \\
\text { assessment are the learners } \\
\text { and those who facilitate } \\
\text { learning. Establishing clear } \\
\text { learning expectations and } \\
\text { identifying the methods of } \\
\text { assessments are essential } \\
\text { steps to creating partnerships } \\
\text { between groups that can } \\
\text { improve learning. }\end{array}$ & $\begin{array}{l}\text { - Encourages stakeholders to think about } \\
\text { assessment from the perspective of the student and } \\
\text { faculty or staff member } \\
\text { - Encourages assessment designers to design the } \\
\text { process with improvement as the primary inspiration } \\
\text { and accountability as secondary }\end{array}$ \\
\hline Collaboration & $\begin{array}{l}\text { The best ideas are formed } \\
\text { and embraced when } \\
\text { everyone collectively } \\
\text { contributes to a shared } \\
\text { purpose through an ongoing } \\
\text { dialogue. All of the Big ldeas } \\
\text { depend on authentic } \\
\text { collaboration for their } \\
\text { legitimacy. }\end{array}$ & $\begin{array}{l}\text { Underlies collaborative governance, Valencia's } \\
\text { strategic and initiative planning process, and the } \\
\text { process through which Big Ideas are formed }\end{array}$ \\
\hline
\end{tabular}

With the Big Ideas in place, Shugart and his team developed processes to involve stakeholders from across campus in elaborating the Big Ideas, determining strategic goals aligned to them, and designing concrete strategies for pursuing the goals. One important change Valencia made was reconstituting its shared governance model around a set of "governance councils" of faculty, staff, and administrators focused on administration, faculty, and learning. These councils, which decide through consensus, inform their decisions and turn ideas into action by commissioning diverse "collaborative work teams" to address particular problems. Team members, including executive sponsors, key stakeholders, and faculty and staff with expertise relevant to the initiative, are trained in collaborative design processes through orientations and leadership seminars. 7 The work teams define a design process, design principles, participants, intended outcomes, rough schedule, decision making plan, and communication plan for their area of focus, and implement the plans after review by the governance council that commissioned the work. In addition to the student success initiatives described below, this process has been used to address topics that include faculty compensation, the tenure process, post-tenure review, the academic schedule, and instructional support systems.

Valencia's governance councils, its Big Meetings, and its Big Ideas all represent crucial infrastructure for the authentically collaborative approach that the institution brings to strategic planning and initiative design. Much of Valencia's success in implementing

\footnotetext{
${ }^{7}$ For more on the latest iteration of Valencia's shared governance model, including training resources for collaborative work teams, see http://valenciacollege.edu/governance/.
} 
countless student success initiatives (described below), mobilizing faculty participation, and enacting large-scale institutional change can be attributed to these participatory systems and processes, which ensure that stakeholders from across Valencia's campuses play an active role in shaping college programs and culture.

\section{Faculty Development}

Participation in elements of the collaborative design process described so farparticularly the Big Meetings-is broad-based. But due to physical and temporal constraints, deep engagement in these activities is limited. Yet two fundamental beliefs that guide Valencia's design methodology require deeper engagement by a wide swath of the campus community. First, there is the notion that the best ideas for helping students succeed come from individuals who are the most directly involved in students' college experiences, and especially students' learning experiences. Second, there is the belief that the best way to develop these ideas into effective innovations, and to bring them from the fringes to the center of Valencia's work, is through a dialog that engages a multitude of experiences with data, research, relevant theory, and, most importantly, other "on-the-ground" perspectives.

Valencia's faculty development program has been designed to meet these needs. Notable for its rigor and comprehensiveness, faculty development at Valencia also acts as a tool of collaboration through which the Big Ideas are constantly engaged and through which student success initiatives are conceived, developed, and institutionalized.

The Office of Faculty Development was launched in the early 2000s in response to Valencia's enhanced emphasis on student learning. One of the Office's initial areas of focus was redesigning Valencia's tenure process, which at the time was not well-aligned to the promotion of student success. ${ }^{8}$ The tenure process, like Valencia's other faculty development programs, is structured around seven educator competencies that Valencia instructors are expected to master. These include assessment, inclusion and diversity, learning-centered teaching strategies, LifeMap, outcomes based practice, professional commitment, and the scholarship of teaching and learning. When a faculty member pursues tenure, she designs an Individualized Learning Plan (ILP) through which she will develop each of these seven competencies. A central part of the ILP is an actionresearch project, or a small-scale research project that investigates "questions regarding

\footnotetext{
${ }^{8}$ For a more detailed explanation of the development of Valencia's unique tenure process and the TLA, see "Building a Faculty Culture of Student Success," The Aspen Institute (February 2013), http://www.aspeninstitute.org/sites/default/files/content/docs/ccprize/BuildingaFacultyCulture.pdf.
} 
student learning that are directly related" to a faculty member's practice. ${ }^{9}$ In this project, faculty members implement changes in their teaching, evaluate the results of their changes, and write up their findings for review. In addition, faculty members must take 50 hours of professional development coursework related to their ILP, and work with a committee of senior faculty and facilitators to guide their progress on their ILP.

As the Office of Faculty Development built up its infrastructure and offerings to support its learning-centered tenure review process, it expanded faculty development programs to support adjuncts and tenured faculty, which includes counselors and librarians. These include a wealth of courses designed to advance one or more of a participant's seven competencies, certifications for associate and adjunct faculty, instructional development tailored towards specific curricular programs, peer observations and evaluations, and development for online teaching and learning. ${ }^{10}$

During our visit to Valencia, we had the opportunity to sit in on the final day of Destination, a five-week, summer-term, professional development program operated by the Office of Faculty Development. During Destination, participating faculty members design classroom interventions related to a variety of topics in teaching and learning. This year's topics included flipped classroom models, infusing student college readiness skills into first year courses, and action-research plans. ${ }^{11}$ In our visits to multiple Destination sections, we saw many elements of Valencia's approach to collaborative design at work, including data-driven methods for designing faculty interventions and a workshop-based approach to articulating and fleshing out early ideas.

\section{Faculty development programs ... serve as incubators for new ideas that, when promising, can eventually be scaled into initiatives from the classroom up.}

\footnotetext{
${ }^{9}$ See "Valencia's Tenure Process Components,"

https://valenciacollege.edu/faculty/development/tla/3year/Tenure/documents/ValenciaTenurePathNarrativeUpdated9.13.1

2.pdf and "Action Research", Teaching and Learning Academy, Office of Faculty Development, Valencia College, https://valenciacollege.edu/faculty/development/tla/actionResearch/.

${ }^{10}$ Office of Faculty Development, Valencia College, http://valenciacollege.edu/faculty/development/.

11 "Destination," Office of Faculty Development, Valencia College, https://valenciacollege.edu/faculty/development/programs/destination/.
} 
Faculty development programs like Destination function as tools for collaboration crucial to Valencia's process of institutional change in two main ways. They serve as incubators for new ideas that, when promising, can eventually be scaled into initiatives from the classroom up. They also provide venues for faculty to engage with college-wide initiatives and to institutionalize new programs in individualized ways. We were able to see both dynamics at work in our observation of the 2015 session of Destination.

For example, two Destination sections this year were "Circles of Innovation" courses, which bring faculty members together to share their self-initiated classroom innovations with one another. ${ }^{12}$ The program, which is sustained throughout the academic year through monthly meetings, is designed to help faculty members transform individuallygenerated "slow-hunches" into "new forms of Great Teaching" through collaboration, collective problem-solving, and discussion. Valencia's “Innovation Funnel," then provides a system through which the most promising ideas can be brought from trial to broader application to full-scale adoption, backed by both evidence and financial investment. Supplemental Instruction, discussed later on this report, is an example of an initiative that was scaled and institutionalized through this process. By functioning as part of a larger system through which faculty-designed initiatives are identified and brought to scale, "Circles of Innovation" puts into practice the collaborative design tenets that the best people to solve problems related to student success are those who work with those students, and best way to mainstream their solutions is through research and consensus.

We also saw an example at Destination of the way in which faculty development programs help faculty integrate college-wide initiatives. One Destination section this year had gateway course faculty members develop projects to incorporate LifeMap college success skills into their curricula, a crucial part of the New Student Experience. During the course, participating faculty members learned about LifeMap skills and how to promote them, and then developed their own plans to infuse LifeMap skills into their courses in the coming term. Participants will implement and assess their plans in Fall 2015, with support from colleague mentors.

\section{Collaboratively Designed Student Success Initiatives}

Valencia has used its collaborative design process and faculty development program to formulate, develop, and institutionalize numerous student success initiatives.

Supplemental Learning emerged in the classrooms of individual faculty members in the late 1990s, and based on indications of effectiveness, was scaled throughout the

12 "Circles of Innovation," Valencia College, http://circlesofinnovation.valenciacollege.edu/. 
institution in the 2000s. In this program, faculty identify students who have been successful in their courses to "retake" the course as model students and lead informal support sessions for students enrolled in the course for the first time. Because the peer tutors experience the courses as the enrolled students experience it, the program quite directly embraces the Big Idea that "the college is how the students experience us, not how we experience them." Supplemental Learning is used in both upper level and developmental courses. ${ }^{13}$

\section{Valencia has used its collaborative design process and faculty development program to formulate, develop, and institutionalize numerous student success initiatives.}

Initiated by Valencia's 2001 strategic plan, a suite of programs and policies to support the "Start Right" Big Idea focus on ensuring that students have a strong start to each semester. Some of the specific initiatives in this category include advising and orientation that occur before the semester begins; required application two weeks before class starts; and strict enforcement of prerequisite requirements to ensure that students are academically prepared for each course. Another related program is "Flex Start," which offers condensed versions of several of Valencia's most important "front door" courses. If a student misses the registration deadline for a particular course or has to start early or end late for other reasons, she can register for a Flex Start course that meets for fewer weeks but maintains the contact hours required of a typical semester. This is a particularly valuable allowance for students who work full-time or have families. ${ }^{14}$

Valencia's Program Learning Outcomes Assessment has positioned the school as a leader in learning assessment. Since 2004, Valencia's Learning Council (now Learning Leadership Council) has developed general education learning outcomes and aligned assessments, and supported each program in the creation off its own learning outcomes

\footnotetext{
13 "Supplemental Learning," Valencia College, http://valenciacollege.edu/supplemental-learning/. As Valencia institutionalized the practice, they took many cues from the University of Missouri-Kansas City, a pioneer in supplemental instruction. See "The International Center for Supplemental Instruction," University of Missouri-Kansas City," http://info.umkc.edu/si/.

${ }^{14}$ See Ann Puyana and Sandy Shugart, "Strategic Learning Goal 2: Start Right," https://valenciacollege.edu/lci/essays/Goal2Essay.htm and Sandy Shugart and Joyce Romano, "Focus on the Front Door of the College," (2011), http://president.valenciacollege.edu/president/files/2011/shugart unprepared student main.pdf.
} 
and assessment plans. ${ }^{15}$ Every year, each program goes through a process of revising the outcomes and assessment plan, administering the assessments, analyzing results, and determining whether any changes to curriculum, sequence, or supports are needed, as well as how to assess those changes after they are implemented. Valencia now hosts an annual conference on learning assessment pitched at community colleges, in which it presents speakers and organizes workshops on effective assessment practices.

In 2005, Valencia became a first-round Achieving the Dream (ATD) college. In addition to refining its Supplemental Learning Program, ATD helped Valencia develop Learning in Community (LinC), in which students take related or sequenced courses as a cohort and their instructors work together and with Success Coach to provide additional support. Since LinC's implementation, Valencia has continued to leverage it for other student success initiatives. For example, when Valencia joined fifteen other early ATD colleges in 2009 in the Developmental Education Initiative, its efforts to improve success rates in developmental education focused on expanding LinC, as well as Supplemental Learning, for students in remedial courses. LinC now includes courses in developmental math, Student Life Skills, composition, U.S. government, and college-level algebra, among others. ${ }^{16}$

\footnotetext{
${ }^{15}$ For an overview of program assessment see "Program Learning Outcomes Assessment," http://valenciacollege.edu/academic-affairs/institutional-effectiveness-planning/institutional-assessment/PLOA/ and Melissa Pedone and Allison Sloan, "Evidence of Learning," in Coming to Terms with Student Outcomes Assessment: Faculty and Administrators Journeys to Integrating Assessment in their Work and Institutional Culture, ed Peggy Maki (Sterling, VA: Stylus Publishing, 2010).

16 "Learning in Community," Valencia College, http://valenciacollege.edu/linc/. See also "Increased Retention and Persistence," Achieving the Dream (2010), http://achievingthedream.org/resource/113/increased-retention-andpersistence-case-studies. For more about the Developmental Education Initiative, see Janet Quint, Shanna Jaggars, D. Crystal Byndloss, Asya Magazinnik, "Bringing Developmental Education to Scale: Lessons from the Developmental Education Initiative" (January 2013), http://www.mdrc.org/sites/default/files/Bringing\%20Developmental\%20Education\%20to\%20Scale\%20FR.pdf.
} 


\section{Table 2. Selected Valencia Student Success Initiatives}

\begin{tabular}{|c|c|c|}
\hline Initiative & $\begin{array}{l}\text { Year } \\
\text { Institutionalized }\end{array}$ & Summary \\
\hline LifeMap & 1999 & $\begin{array}{l}\text { A developmental advising model and program that links all } \\
\text { components of Valencia (faculty, staff, courses, } \\
\text { technology, programs, services) into a personal itinerary to } \\
\text { help students succeed. LifeMap sets the normative } \\
\text { expectation that students have an educational and career } \\
\text { plan early on in their enrollment, based on distinct phases } \\
\text { of progression through college. }\end{array}$ \\
\hline Start Right & 2001 & $\begin{array}{l}\text { A collection of initiatives and reforms designed to ensure } \\
\text { students start off college and each semester in a way that } \\
\text { sets them up for success. Policies include earlier advising } \\
\text { and orientation, required registration two weeks before } \\
\text { class, strictly enforced prerequisites and placement } \\
\text { policies, and "Flex Start," which offers classes that start } \\
\text { later or end earlier than official term dates without reducing } \\
\text { the number of hours the student spends in that course. }\end{array}$ \\
\hline
\end{tabular}

\begin{tabular}{|c|c|c|}
\hline $\begin{array}{l}\text { Supplemental } \\
\text { Instruction }\end{array}$ & 2004 & $\begin{array}{l}\text { Students who have already been successful in a course act } \\
\text { as an "SL leader" and lead informal support sessions for } \\
\text { students currently enrolled in the course. SL Leaders are } \\
\text { identified by faculty and take the course and experience it } \\
\text { just as other students would. }\end{array}$ \\
\hline $\begin{array}{l}\text { Program Learning } \\
\text { Outcomes } \\
\text { Assessment }\end{array}$ & 2006 & $\begin{array}{l}\text { Students are assessed at the end of their degree program } \\
\text { to gauge how well the program's curriculum, sequencing, } \\
\text { and instruction achieved its learning goals. Assessment } \\
\text { results are used to improve programs and learning. }\end{array}$ \\
\hline $\begin{array}{l}\text { Learning in } \\
\text { Community }\end{array}$ & 2006 & $\begin{array}{l}\text { A pairing of two or more courses (with the same or different } \\
\text { instructors) with integrated curricula. A group of students } \\
\text { take both courses together, and instructors work with one } \\
\text { another and with a Success Coach to help support the } \\
\text { student cohort. }\end{array}$ \\
\hline DirectConnect to UCF & 2006 & $\begin{array}{l}\text { A partnership with UCF that guarantees transfer admission } \\
\text { to Associate's degree graduates from Valencia and other } \\
\text { Florida State Colleges. }\end{array}$ \\
\hline $\begin{array}{l}\text { New Student } \\
\text { Experience }\end{array}$ & 2013 & $\begin{array}{l}\text { A collection of curricular and co-curricular interventions } \\
\text { designed to support student success during a student's first } \\
\text { fifteen credits at Valencia. }\end{array}$ \\
\hline
\end{tabular}




\section{Direct Connect to UCF}

In 2006, Valencia joined DirectConnect to $U C F$, a partnership that guarantees Valencia associate's degree graduates admission to UCF.17 While the partnership on which DirectConnect to UCF was built includes several other Florida state colleges, ${ }^{18}$ Valencia is UCF's large enrollment partner: 52 percent of all DirectConnect to UCF transfers come from Valencia College, and many students start out at Valencia with the ultimate goal of transferring to UCF.19

DirectConnect to UCF has had a noticeable impact on instruction, curriculum, and advising at Valencia. It has enhanced Valencia's focus on providing students with connection and direction, and now all Valencia DirectConnect UCF students work with dedicated program advisors who help students prepare for their transition and develop plans to graduate from both Valencia and UCF in a timely manner. Through formal and informal processes, DirectConnect to $U C F$ has also pressed instructors to improve instructional quality to better prepare their students to succeed at a selective, four-year research university.

When DirectConnect to UCF launched in 2006, Valencia had already worked with LifeMap, its developmental advising model, for nearly a decade. As such, Valencia faculty and advising staff had some tools to help students prepare for a smooth transfer between institutions and plan for success at UCF. However, as DirectConnect to UCF has developed, faculty, staff, and leaders from all partner schools have been integral in growing the partnership. These stakeholders employ many of the techniques characteristic of Valencia's collaborative design methodology to develop and improve upon a broad range of programs to ensure that transfer students are well-prepared for $\mathrm{UCF}$ and graduate at the same rates as first time in college (FTIC) students. ${ }^{20}$

\footnotetext{
${ }^{17}$ For more on DirectConnect to UCF and its development, see Saundra Amrhein, "Where Dreams Come True," Politico Magazine (June 18, 2015), http://www.politico.com/magazine/story/2015/06/orlando-what-works119159.htm|\#.VZK4XVeXFwU.

${ }^{18}$ Partner colleges include Eastern Florida State College, Lake Sumter State College, Seminole State College, and Daytona State College, which joined the consortium in 2014. Though these schools serve primarily as associate's degreegranting institutions, they also grant bachelor's degrees in select fields, hence the designation state colleges.

${ }^{19}$ See "DirectConnect," Excelencia in Education, http://www.edexcelencia.org/program/directconnect. See also DirectConnect to UCF Student Focus Groups: A Qualitative Study," (November 2012), http://www.collegeaccess.ucf.edu/download/attachments/360479/DirectConnect\%20to\%20UCF\%20Student\%20Focus\%2 0Groups.pdf?version $=1 \&$ modificationDate $=1367511666830 \&$ api $=v 2$.

${ }^{20}$ UCF transfer students have a five-year graduation rate of 67 percent; UCF FTIC students have a six-year graduation rate of 68 percent. Data provided by UCF's Director of Institutional Research.
} 
One example of this is the annual College Access Summit. Each year, faculty, administrators, and advisors from UCF, Valencia, and the other partner colleges convene to discuss as a large group and work in discipline-specific teams on steps to ease students' transition. In April 2015, we had the opportunity to observe part of the 2015 summit and were impressed by the collaborative way in which individuals across institutions used data compiled by UCF's institutional research office and their own experiences with students to identify challenges and develop solutions. The similarity in structure between the College Access Summit, on one hand, and Valencia's Big Meetings and the working groups we observed in the Destination faculty development program, on the other hand, is striking.

In addition to the College Access Summit, UCF and its partner colleges participate in a shared data resource group, develop curricula together, and collaborate on grants. Crossinstitutional working groups for enrollment services, advising, student affairs, academic affairs, financial aid, and registrars meet multiple times each year. ${ }^{21}$

\section{The New Student Experience}

Valencia's Big Ideas have become somewhat iconic, but they are open to bottom up innovation in the same way that specific initiatives are. Valencia's newest Big Idea, the New Student Experience (NSE), expands on many of its curricular innovations in front door courses and integrates them with a variety of co-curricular supports. Its design and implementation process nicely illustrates the sustained utilization of Valencia's collaborative design methodology from a program's inception to its institutionalization.

NSE is intended to provide a coordinated experience for all Valencia students with fewer than 15 college-level credits. These include a required credit-earning first-year seminar; the integration of student success skills into select program introductory courses; the alignment of general education courses; career and academic advising that includes the development of an individualized education plan; and a variety of co-curricular opportunities that "encourage new students to discover, create and reinforce their academic pathways and instill a sense of belonging to the Valencia culture." ${ }^{22}$ Students are expected to emerge from NSE with a sense of purpose at the school; an educational and financial plan; a sense of personal connection with the Valencia community; an aligned pathway to their educational and career goals; useful preparation for success at

${ }^{21}$ See The College Access Initiative, http://www.collegeaccess.ucf.edu/display/CAl/College+Access+Initiative

${ }^{22}$ See "New Student Experience," http://valenciacollege.edu/academic-affairs/new-student-experience/. For an in-depth review of the planning and design process, we referred to "Quality Enhancement Plan: The New Student Experience," (September 2013), provided by Kurt Ewen. For resources used during the planning process, see "Our Next Big Idea," http://valenciacollege.edu/ournextbigidea/timeline.cfm. 
college, and a sense of place and awareness of college support systems. Valencia refers to these outcomes as the "Six Ps."

NSE was initially conceived as the Quality Enhancement Plan (QEP) required for Valencia's Southern Association of Colleges and Schools (SACS) accreditation review in 2012. However, as has often been the case with Valencia's design process, college leaders leveraged more than a decade's worth of student success work to develop NSE as a strategy that was not only pragmatic, but also allowed institutional stakeholders to easily identify cohesion and momentum in Valencia's learning-centered approach. In addition to building on initiatives like Supplemental Learning and LinC, NSE's focus on providing students with direction and ensuring common learning outcomes for new students leveraged principles already in place as part of LifeMap and Valencia's Program Outcome Assessments. ${ }^{23}$ The design process for NSE also incorporated Valencia's previous work with Achieving the Dream and the Developmental Education Initiative, including improvements to "front door courses" and processes that emphasized datadriven inquiry. Finally, NSE's focus on creating an integrated new student experience drew directly from Valencia's work with the John Gardner Institute's Foundations of Excellence program. During a Foundations of Excellence self-study in 2009 and 2010, faculty and administrators focused on institutional practices related to students' early experiences at the college and identified the need for a more coordinated set of programs. ${ }^{24}$

The process through which Valencia decided to focus on new students' experiences for its QEP illustrates the collaborative design dynamic. The QEP Leadership Team launched the process with a series of Reading Circles, in which groups of faculty, administrators, and students reflected on their Valencia experiences in light of shared reading materials. ${ }^{25}$ Then, a March 2012 Big Meeting involving hundreds of stakeholders generated four "emerging ideas" to consider as candidates for the QEP focus. ${ }^{26}$ Following the Big Meeting, the QEP Leadership Team organized 14 "Big Idea Groups," comprised

\footnotetext{
23 “Quality Enhancement Plan: The New Student Experience," p. 13.

24 "Starting Right: The Story Continues. Foundations of Excellence Final Report and Recommendations," Valencia College (May 7, 2009), http://valenciacollege.edu/academic-affairs/institutional-effectiveness-planning/institutionalassessment/documents/FoEFinalReport-ApprovedbyCLC5-7-09.pdf.

25 The QEP Leadership team included four faculty leaders, the Assistant Vice President for Assessment and Institutional Effectiveness, and the Vice President of Student Affairs; the QEP Core Team consisted of faculty members, campus deans, and administrative staff from a variety of campus departments.

${ }^{26}$ NSE was one of these "emerging ideas," and drew from data that showed that the greatest indicator of a student's success at Valencia was her success in her first attempts in her first five college courses. New Student Experience articulated the notion that "to support student learning, students need a holistic experience that is academically and socially engaging while providing connection and direction," and focused these efforts on students who were earning their first fifteen credits at Valencia.
} 
of 280 faculty members, to discuss each of the candidates. To capture student input, faculty members organized student focus groups and all enrolled students were surveyed about their experiences in relation to the four emerging ideas.

In November 2012, the 14 Big Idea Groups met to share their findings, and NSE emerged by consensus as the most urgent need and logical next direction for the Valencia community. As the QEP Leadership Team developed an outline of the QEP, they continued to solicit comments, recommendations, and suggestions from faculty and staff. The outline was reviewed during a 2013 summit and approved by 111 of the 130 faculty and staff members in attendance. Soon after, the QEP Leadership Team appointed a collaborative design team to flesh out the details, with ongoing solicitation of input from stakeholders.

As NSE has been implemented, Destination and other faculty development programs have ensured that the initiative is tailored to the specific needs of faculty members' students. As discussed above, faculty members work together and with more senior faculty to develop individualized plans to infuse NSE Success Skills into their courses in ways that work best with their subject matter, teaching styles, and students' needs.

\section{Evidence of Impact}

Valencia's success has been widely recognized. In 2009, Valencia was awarded Achieving the Dream's inaugural Leah Meyer Austin Award for its "excellent execution of datainformed initiatives to close performance gaps among students from different ethnic and economic backgrounds." In 2012, the college received the Aspen Institute's inaugural Aspen Prize for Community College Excellence for achieving exceptional student outcomes. Valencia's leaders speak frequently in venues across the country about the college's initiatives and its process of institutional change. ${ }^{27}$

This recognition is well warranted: from 2005 to 2014, through a combination of enrollment increases and improvements to completion rates, Valencia increased the number of Associate of Arts degrees it awarded to degree-seeking students who completed within five years from 926 to 2,007. During this time, the number of first time

27 "Leah Meyer Austin Award," Achieving the Dream, http://achievingthedream.org/resources/initiatives/leah-meyer-austinaward. For Valencia's application for the Aspen Prize, see "Institutional Assessment," Valencia College, http://valenciacollege.edu/academic-affairs/institutional-effectiveness-planning/institutionalassessment/aspenprizeapplication.cfm. For the Aspen Institute's profile on Valencia, see "Valencia College," College Excellence Program, Aspen Institute, http://www.aspeninstitute.org/policy-work/college-excellence/2011-aspenprize/valencia-college. 
in college, degree-seeking students grew from 3,873 to 5,926, and the five-year graduation rate for those students increased from 24 to 34 percent. ${ }^{28}$

\section{As Valencia deepened its student success work in the early 2000s, developmental course success, persistence, and credit attainment rates all increased.}

As Valencia deepened its student success work in the early 20oos, developmental course success, persistence, and credit attainment rates all increased. From 2002 to 2010, the share of students who had completed developmental education within two years grew from 48 percent to 80 percent in reading, 55 percent to 78 percent in writing, and 34 percent to 61 percent in math. ${ }^{29}$ Over the same period of time, fall to spring persistence increased from 79 percent to 86 percent. From the Fall 2003 cohort to the Fall 2008 cohort, the portion of FTIC degree-seeking students who had completed 30 credits within three years grew from 41 percent to 53 percent.

More recently, progression rates for degree-seeking students have decreased. From 2011 to 2013, the portion of students who had successfully completed developmental coursework within two years decreased from 78 percent to 69 percent in writing, 78 percent to 72 percent in reading, and 61 percent to 46 percent in math. Persistence and credit attainment rates have also declined slightly. ${ }^{30}$ These decreases made the need for

\footnotetext{
28 "Graduation Rates by Number of Mandated Areas: Fall Cohort FTIC Degree-seekers over 5 years," Strategic Indicator Report: 2013-2014 Student Progression," Valencia College (March 2015), http://valenciacollege.edu/academicaffairs/institutional-effectiveness-planning/institutional-research/Reporting/StrategicIndicators/documents/1314StudentProgression-updated20150526.pdf. From 2005 to 2009, total degree seeking students (all levels) grew from 23,691 (81 percent of all enrolled students) to 36,436 (84\% of all enrolled students). See "Percent of Full-Time Students by Degree Intent (Fall Term Only)," in "Strategic Indicator Report: 2013-2014 Student Demographics," Valencia College (March 2, 2015), http://valenciacollege.edu/academic-affairs/institutional-effectivenessplanning/institutional-research/Reporting/Strategic-Indicators/documents/1314StudentDemographics.pdf.

${ }^{29}$ Valencia College report to Department of Education, http://webcache.googleusercontent.com/search?q=cache:IvCHjAFetogJ:www2.ed.gov/documents/collegecompletion/valencia-college- 2 . doc $+\& \mathrm{~cd}=10 \& \mathrm{hl}=\mathrm{en} \& \mathrm{ct}=\mathrm{clnk} \& \mathrm{gl}=\mathrm{us}$.
}

${ }^{30}$ After remaining steadily above 85 percent for several years, fall to spring persistence rates for degree-seeking FTIC decreased by nearly ten percentage points in the fall of 2011, and have remained in between 75 percent and 80 percent in recent years. (Fall to fall persistence rates, on the other hand, have remained remarkably steady around 70 percent.) Around the same time that persistence rates declined, credit attainment rates decreased as well. After peaking at 53 percent in Fall 2008, the portion of degree-seeking FTIC students who earned 30 credits within three years decreased to 44 percent for the Fall 2010 cohort and 46 percent for the Fall 2013 cohort. "Strategic Indicator Report: 2013-2014 
an integrated new student experience especially pressing around the time that Valencia sought SACS reaccreditation in 2012.

Faculty development at Valencia is extensive, and appears to have steeped instructors in the Big Ideas and other college-wide initiatives. During academic year 2013-2014, the Office of Faculty Development offered 383 courses in which 958 of Valencia's roughly 1,500 faculty members participated (most participants took three or four courses). Of a sample of 102 associate faculty members surveyed about their faculty development experiences, $75 \%$ reported that the program helped them employ strategies to guide students to become active learners, and 100\% strongly agreed or agreed that the program enhanced their knowledge of Valencia's seven essential competencies of an educator. ${ }^{31}$

During our visit to Destination, we saw similar evidence of the interest and investment in the faculty development process among participants. Faculty members presented their ideas and projects enthusiastically, and offered numerous, cogent questions and suggestions about their colleagues' projects. On several occasions, presenting participants indicated that their colleagues' comments provided insights that would help them improve their project. In individual conversations, participants consistently endorsed the value of Destination. Each participant we spoke with reported a clear plan to implement and assess projects in the coming semester. Additionally, in Valencia's own surveys and feedback forums, Destination participants have reported that the program had a significant impact on their teaching, their ability to perform action research, and their confidence using technology in the classroom..$^{32}$

From fall 2007 (a year after DirectConnect to UCF was implemented) to fall 2013, the number of DirectConnect to UCF students at Valencia grew from 7,197 (22 percent of all enrolled students) to 21,696 (51 percent of all enrolled students). Success rates for students once they transfer to UCF is not available at the college level, but, across all partner colleges, DirectConnect to UCF students have a graduation rate of 67 percent, only one percentage point lower than UCF's FTIC students.

DirectConnect to $U C F$ also appears to have changed the value proposition for students entering Valencia. We spoke with two DirectConnect to UCF students during our visit, who explained that the guaranteed transfer program was their reason for enrolling at Valencia. These students reported satisfaction with their decision to "DirectConnect"

Student Demographics," Valencia College (March 2, 2015), http://valenciacollege.edu/academic-affairs/institutionaleffectiveness-planning/institutional-research/Reporting/Strategic-Indicators/documents/1314StudentDemographics.pdf.

31 Valencia Annual Faculty Development Report, 2013-2014, provided by Kurt Ewen.

${ }^{32}$ Ibid. 
from Valencia to UCF, and said that they appreciated the small classes, engaged instructors, low costs, and easy commutes that Valencia offered. The students offered particular praise for their advising experiences, indicating that they have received extensive support in charting out plans for completion at both Valencia and UCF. Although our sample is very small, the fact that students participating in Valencia-led focus groups have made similar statements gives us some confidence in the representativeness of the students we met.

Early evaluations of NSE suggest that the program is on track to realize success. On feedback surveys administered to students who took the NSE course in the fall of 2014, more than 80 percent reported that, as a result of the course, they felt prepared to articulate their educational and career aspirations; to design an education and financial plan; to apply the study skills that they had learned; and that they had strengthened their ability to communicate their ideas clearly and effectively. Faculty evaluations of student learning artifacts yielded similar findings, with a substantial majority of students demonstrating robust success skills and educational plans. Seventy-four percent of all students enrolled in the NSE course received an A, B, or C in the course, and students who received these grades in NSE course were successful in their other coursesincluding developmental courses-87 percent of the time. Of students who took the NSE course in fall 2014, 78 percent persisted into the spring of 2015 (90 percent of successful completers persisted), compared to 76 percent for all degree-seeking FTIC students at Valencia. 33

\section{Success Factors}

The people we spoke with at Valencia emphasized that its specific tools and strategies had emerged from a process embedded in their institutional context, and could not simply be exported to other institutions. While this is undoubtedly true, our review of Valencia's experience surfaced several generalized themes relevant to other institutions engaged in large scale reform.

\footnotetext{
33 "Success" is defined as earning an A, B, or C in the course. Developmental education success rates for students who were successful in SLS1122 were higher than college-wide averages. See Dr. Christina Harden, "Valencia College Quality Enhancement Plan: The New Student Experience Fall 2014 Report," Valencia College (March 2, 2015), https://valenciacollege.edu/academic-affairs/new-studentexperience/documents/NSEFall2014ReportREVISED3215.pdf, p. 9. For college-wide persistence rates for degreeseeking FTIC, see "Strategic Indicator Report," http://valenciacollege.edu/academic-affairs/institutional-effectivenessplanning/institutional-research/Reporting/Strategic-Indicators/documents/1314StudentDemographics.pdf.
} 


\section{Collaborative Design}

Valencia's collaborative design process has been the major focus of this report, but it is worth re-emphasizing the importance of the structure to Valencia's transformation. Collaborative design has helped Valencia develop programs tailored to its circumstances, has surfaced and scaled ideas from front-line staff, and has enabled local adaptation of college-wide initiatives. Just as important, it has served as a mechanism through which administrators and faculty at all levels develop a sense of ownership of Valencia's policies and initiatives, ensuring widespread mission alignment across the institution. Particulars like the Big Ideas, Big Meetings, and collaborative design teams are idiosyncratic to Valencia, and could not simply be exported and adopted by another institution. But the underlying concept of a process in which "working theories" are developed into concrete strategies through a coordinated series of consensus-building gatherings and cross-functional working teams operating according to a set of design principles is certainly capable of replication in other contexts.

\section{Collaborative design has helped Valencia develop programs tailored to its circumstances, has surfaced and scaled ideas from front-line staff, and has enabled local adaptation of college-wide initiatives.}

\section{Taking Faculty Development Seriously}

Valencia's systematic and intensive faculty development is another standout feature that has contributed to its success. As discussed extensively above, Valencia has developed a robust curriculum for its faculty, offering training in various forms, at various times of year. The development program includes training in the substance of teaching, such as pedagogy, course design, and integrating student support. It also includes research skills, especially instructional research. And, notably, it includes training in the processes of college governance-such as skills for contributing to collaborative design. Valencia has invested in making the development program relevant to its faculty's work, ongoing rather than discrete, and aimed at different styles. All of this has made the development program an effective vehicle for integrating college-wide initiatives, as well as a source for new ideas. 


\section{Leveraging existing systems to implement new initiatives}

Valencia has rarely designed an initiative from scratch. Instead, it aims for continuity among its initiatives, and uses systems established or values articulated in previous initiatives to build momentum for new ones. For example, NSE builds on work done in the Foundations of Excellence self-study, Achieving the Dream, the Developmental Education Initiative, and Valencia's long-standing strategic focus on providing students with support early on in college. Valencia's work with Achieving the Dream also influenced the institution's approach to data-driven inquiry and bringing initiatives to scale, both of which now structure Valencia's day-to-day decision-making process.

\section{Valencia has rarely designed an initiative from scratch. Instead, it aims for continuity among its initiatives, and uses systems established or values articulated in previous initiatives to build momentum for new ones.}

Valencia's integrated and coherent approach to reform serves both pragmatic and cultural purposes. Because an initiative like NSE built on previous work and was in an area in which the college had already invested resources, achieving its stated goals seemed more manageable to stakeholders and accreditors. Additionally, taking an approach that makes clear how initiatives fit with one another-and into a larger set of shared values-positions reforms not as stand-alone tactics, but rather as pieces of a larger institutional strategy and mindset that everyone has a part in shaping.

\section{A "learning-centered" budgeting and resource allocation process}

When Sandy Shugart began his presidency in 2000, one of his first priorities was redesigning the budgeting process so that each cycle began with a set of guidelines that connected the budget to Valencia's learning-centered strategic priorities. Each year, Valencia delivers a "Budget Planning Principles" report to the Board of Trustees that explicitly outlines how the budget expresses these priorities. 34 Shugart reports that changing the budgeting process was a crucial step in bringing Valencia's learningcentered focus from the fringes to the center of Valencia's culture.

\footnotetext{
${ }^{34}$ See, for example, "Budget Statement for 2012-2013," Prepared by the Budget and Financial Advisory Group (BFAG) (September 2012), https://valenciacollege.edu/budget/documents/Budget Statement 2012-13.pdf.
} 


\section{Though finding resources to fund initiatives remains a constant challenge, Valencia's learning-centered budgeting process ensures that efforts to improve student success remain a top priority.}

Structuring the budgeting process in this way has allowed Valencia to make strategic use of its limited resources while keeping tuition and fees low. In order to fund learningcentered initiatives in recent years, Valencia has leased bandwidth on campus owned-cell towers, lowered energy costs, enrolled more international students, and aggressively pursued grants that align with the college's strategic priorities. Though finding resources to fund initiatives remains a constant challenge, Valencia's learning-centered budgeting process ensures that efforts to improve student success remain a top priority.

\section{Succinct, galvanizing "Big Ideas" that guide decision-making}

Shared language, values, and assumptions are all critical pieces of an effective organizational culture. Valencia has been especially successful at formulating, articulating, and institutionalizing its "Big Ideas," which facilitate collaboration by providing all stakeholders with a set of guiding theories as they engage in design and planning. A large part of the reason that Big Ideas have succeeded at providing a guiding logic for Valencia's work can be attributed to the collaborative way in which they have been formulated and institutionalized, as illustrated by the NSE development process. As such, faculty, staff, and administrators are invested in these working theories, and feel as if they have a stake in in their implementation.

However, the success of Valencia's Big Ideas can also be attributed to the uniform way in which they have been articulated throughout the institution. Framing this deeply rooted set of values is a shared vocabulary that structures group meetings and galvanizes innovation around easily articulated rallying points. While the role of this common language in sustaining Valencia's culture is most apparent in the succinct articulation of its Big Ideas, many other programs are also framed by signifiers that summarize their underlying principles. Examples include language related to Valencia's core competencies, "the Big A to the Big S" which signifies the philosophy behind the LifeMap developmental advising model, and the "Six P's" which summarizes the intended outcomes of the New Student Experience. This vocabulary provides stakeholders at all levels with accessible touchstones when designing, assessing, and articulating their work. 


\section{Strong leadership}

Although the groundwork for Valencia's transformation was laid before Sandy Shugart began his term as president, it was his leadership that galvanized the entire institution around a learning-centered approach. Shugart's management style and long tenure have earned a high level of trust and respect from administrators and faculty, and he has been uniquely successful at nurturing a shared culture within the institution. Upon his arrival at Valencia, Shugart took concrete steps to establish student learning and success as top priorities, and put in place infrastructure that would ensure this focus.

Since then, Shugart's success as a leader has been driven by a distinct self-awareness of both his strengths and limitations as a college president. Shugart has been particularly effective at articulating Valencia's values to internal and external stakeholders alike. While Valencia had already received national attention for its student learning work before Shugart's arrival (in fact, this was part of the reason he was attracted to Valencia), Shugart's abilities as a communicator have solidified Valencia's spot in the national spotlight, and have helped to nurture a shared culture within the institution. However, Shugart remains aware of his constraints as president of a large, multi-campus institution, and his willingness to share responsibility with those on the "front-lines" of Valencia's learning-centered work has been an invaluable part of Valencia's transformation.

Shugart has also empowered a strong team, including several key staff who led the student success work before he arrived. To cite just a few examples, Joyce Romano, vice president of student affairs, has been the driving force behind LifeMap since its initiation, and has played a lynchpin role in every other initiative described in this report. With support from Shugart, Romano has been able to infuse her developmental approach to student support into nearly every aspect of college policy and practice, and is largely responsible for the integration of advising and academics characteristic of Valencia. Kurt Ewen was a key partner with Romano on many of the student success initiatives of the past fifteen years, and led the design of the learning outcomes assessment system that has become a national model. And Wendi Dew, as the head of the Office of Faculty Development, scaled up and diversified the faculty development offerings into the comprehensive curriculum that exists today.

\section{Remaining Challenges}

Valencia's collaborative approach has been a powerful tool for design, decision-making, and initiative implementation, and appears both formally and informally in Valencia's learning-centered endeavors. As Valencia moves forward with the New Student 
Experience and other student success efforts, it will negotiate a number of challenges that may complicate its collaborative approach or slow the pace of specific initiatives.

One challenge that Valencia is currently negotiating is a new, more decentralized campus governance model, initiated in 2012. Under the new model, campus provosts were replaced with campus presidents who lead their campuses more autonomously. This redesign was rooted in a broad consensus that decentralization was the best way to achieve institution-wide engagement and unleash local innovation, especially in light of differences in student demographics and goals in Osceola County and Orange County. However, striking a balance between college-wide cohesion and campus-specific direction has proved challenging. Leaders at both the college level and the campus level remain unsure of how to define the new relationship between the two entities, and campus presidents' varied approaches to participation in college-wide initiatives has compounded this challenge.

The policy environment in Florida occasionally throws a curveball. For example, a state law that went into effect for the first time in 2014 made developmental education optional for traditional high school graduates. Although Valencia has worked to integrate developmental skills into its college curriculum, the new policy is at odds with Valencia's Start Right principle, which encourages students to take courses for which they are prepared so they can experience early success. ${ }^{35}$ The policy change has forced changes to and puts added pressure on the designers and instructors in Valencia's New Student Experience.

The new developmental education policy also complicates Valencia's efforts to support the students with the greatest developmental needs. While Valencia's degree completion rate for students with needs in all three developmental areas have doubled in the past ten years, these students still lag far behind their peers who are college ready. ${ }^{36}$ There are some promising initiatives underway to address this population. For example, under President Kathleen Plinske, Valencia's Osceola campus has built partnerships with the

\footnotetext{
${ }^{35}$ See Ashley A. Smith, "When You're Not Ready," Inside Higher Ed (June 25, 2015), https://www.insidehighered.com/news/2015/06/25/floridas-remedial-law-leads-decreasing-pass-rates-math-and-english. Though developmental education remains a significant stumbling block for community college students nationwide, interviewees with whom we spoke at Valencia maintain that that making it optional is not the answer, and that, through Supplemental Learning and other reforms, Valencia had improved success rates in developmental courses.

${ }^{36}$ See "Graduation Rates by Number of Mandated Areas," in "Strategic Indicator Report: Student Progression 20132014," Valencia College, March 2015, http://valenciacollege.edu/academic-affairs/institutional-effectivenessplanning/institutional-research/Reporting/Strategic-Indicators/documents/1314StudentProgression-updated20150526.pdf.
} 
Osceola County K-12 school district and a local foundation to increase college-readiness and enrollment among the county's high school students. 37

Another challenge-and opportunity-for Valencia is an ambitious set of projects that focus on data-sharing and analytics. Valencia has begun laying the groundwork for a federated data system with UCF to improve the DirectConnect to UCF transfer experience. It has begun to explore similar partnerships with local K-12 systems to create a longitudinal data system to create predictive algorithms of student success. These initiatives are powerful opportunities for Valencia to improve instruction, advising, and partnerships. However, they will also present technical and logistical challenges, put pressure on resource allocation, and may be complicated by concerns related to datasharing and student privacy.

Finally, while Valencia's approach to resource allocation has allowed it to push forward learning-centered initiatives with success, its limited budget remains a constraint for future endeavors. Valencia spends about \$7,000 per FTE, less than any of the other 28 colleges in Florida's State College System (FCS). The portion of Valencia's revenue that comes from state appropriations is less than that received by 26 out of 28 FCS institutions. ${ }^{8}$ The New Student Experience alone has required that Valencia invest in 21 new faculty members and 16 new advisors, and train both the new and current employees. As Valencia grows, it will have to continue to find efficient ways to scale initiatives without compromising their quality.

\section{Conclusion}

When discussing Valencia's success, President Shugart is careful to emphasize that it would be difficult to replicate Valencia's programs, as well as its distinct approach to change, elsewhere. Valencia's initiatives, culture, and specific tools of collaboration are unique products of a contextualized process. According to Shugart, any institution looking to achieve similar results must go through their own process of inquiry to determine what programs, values, and approaches work best for them. In a colorful

\footnotetext{
${ }^{37}$ See Emily Rogan, "Got College? Boosting Higher Ed Attendance Rates," American Association of Community Colleges $21^{\text {st }}$ Century Center (June 10, 2014), http://www.aacc21stcenturycenter.org/article/got-college-boosting-higher-edattendance-rates/. See also, Jessie Brown, "Promising Directions for K-12 and Community College Partnerships," Ithaka S+R Blog (July 1, 2015), http://valenciacollege.edu/academic-affairs/institutional-effectiveness-planning/institutionalresearch/Reporting/Strategic-Indicators/documents/1314StudentProgression-updated20150526.pdf.

${ }^{38}$ This comparison is based on our analysis. All Florida State Colleges were identified using the Florida Department of Education website, http://www.fldoe.org/schools/higher-ed/fl-college-system/colleges/index.stml. Data on total expenses per FTE and total revenue from state sources were gathered from IPEDS.
} 
metaphor, Shugart notes that other institutions can't just dig up Valencia's trees and plant them; they will have to start with the soil.

\section{Other institutions ... can learn from many aspects of Valencia's collaborative design methodology, especially its emphasis on broad based participation, its investment in data-driven inquiry, and its success in integrating new initiatives with long-held philosophies and goals.}

Certainly, replications of Valencia's Big Ideas, Big Meetings, or even specific initiatives elsewhere would falter. However, other institutions-and especially other community colleges - can learn from many aspects of Valencia's collaborative design methodology, especially its emphasis on broad based participation, its investment in data-driven inquiry, and its success in integrating new initiatives with long-held philosophies and goals. Valencia's success with this model did not happen overnight. Rather, it is the culmination of decades of intentional, focused work organized around clear and consistent shared values. As other institutions explore ways in which they can "redesign" their culture and operations around student success, setting a strong foundation, maintaining a commitment to it, and enlisting a broad range of stakeholders in defining and institutionalizing this culture will be crucial ingredients for reform. 


\section{Appendix}

We conducted the following interviews with Valencia staff, faculty and students on June 11 and 12, 2015:

- Ayanna Collins, Transfer Program Advisor

- Charles Davis, Bachelor of Science Program Advisor

- Lisa Macon Dean, Division of Engineering, Computer Programming, and Technology at Valencia College

- Wendi Dew, Assistant Vice President of Teaching \& Learning and Faculty Development

- Kurt Ewen, Presidential Fellow

- Ed Holmes, Campus Director of Advising

- Chris Klinger, Counselor, Osceola Campus

- Cathy Penfold Navarro, Title III Project Director

- Kathleen Plinske, Campus President, Osceola and Lake Nona Campuses

- Joyce Romano, Vice President of Student Affairs

- Sandy Shugart, President

- Two Valencia DirectConnect to UCF engineering students 